\title{
Accessing and assessing young learner's mathematical dispositions
}

\begin{abstract}
It is argued in this paper that there is an absence of literature relating to research on learner mathematical dispositions, particularly with young learners. Drawing on Kilpatrick, Swafford and Findell's (2001) five interrelated strands of mathematical proficiency, which include: conceptual understanding, procedural fluency, strategic competence, adaptive reasoning and productive disposition, it is argued that there has been little engagement with productive disposition in the field of mathematics education and how we might access and assess this strand. Despite competence in all strands being essential for mathematical proficiency, literature and assessments that seek to establish learner levels of mathematical proficiency have tended to focus on the first four and have neglected the last; productive disposition. Finding ways in which to access student mathematical learning dispositions can be challenging, especially with young learners who struggle to articulate their views. An instrument is shared that the author has designed with doctoral fellow, Debbie Stott, in order to access and assess the productive disposition of learners participating in maths clubs run within the South African Numeracy Chair. The findings that emerge in one Grade 3 club with six learners is shared. These findings are related to the data collected through instruments that assess the other four strands of mathematical proficiency. This enables a holistic picture of learner's mathematical proficiency as intended in the conceptualisation of the interrelated five strands of proficiency.
\end{abstract}

Keywords: productive disposition; five strands of mathematical proficiency, young learners.

Mellony Graven, South African Numeracy Chair, Rhodes University. E-mail: m.graven@ ru.ac.za.

South African Journal of Childhood Education | 2012 2(1): 49-62 | ISSN: 2223-7674 | ๑ UJ
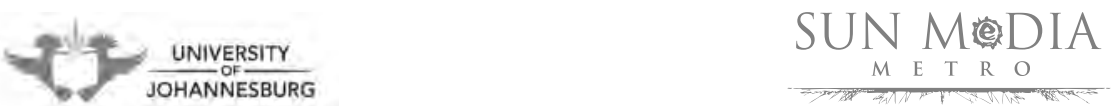


\section{Contextual background and empirical field for the study}

South Africa is facing a crisis in numeracy education as evidenced by sustained poor performance across international, regional and national assessments (cf. Fleisch, 2008; SACMEQ, 2010; Carnoy, Chisholm, Addy, Arends, Baloyi, Irving \& Raab, 2011; DoE, 2008). For many years interventions have focused on improving performance of Further Education and Training (FET), and in particular, improving matric results. However, more recently, there has been increasing acknowledgement that interventions need to begin much earlier in schooling. In this respect the mathematics Education Chairs Initiative appointed two Chairs focused on numeracy education in the early years of schooling. Professor Hamsa Venkatakrishnan holds one such Chair at Wits University and Professor Mellony Graven holds the South African Numeracy Chair at Rhodes University. The focus of these Chairs is twofold: To nurture research in the field of numeracy education that is focused on searching for sustainable ways forward to address the 'crisis' and to improve learner numeracy performance in the schools where we do this work. Our Chair has partnered with numeracy teachers (ranging from Grade 0 to Grade 6) in 15 schools in the broader Grahamstown area to work towards the improvement of numeracy teaching and learning in these schools. This partnership enables access to numeracy classrooms as the empirical field for research. The teacher development programme of our South African Numeracy Chair at Rhodes University is the Numeracy Inquiry Community of Leader Educators (NICLE). This programme involves the establishment of a supportive community where teachers engage with numeracy concepts and the teaching of numeracy in fortnightly seminars and workshops. Additionally our Chair includes direct learner focused interventions in the form of mathematics clubs as an intervention strategy aimed at improving numeracy learning.

The first pilot club began in August 2011. In 2012 we have established one Grade 2 club, one Grade 4 club and three Grade 3 clubs, one of which is the focus of this paper. The clubs take place in varied contexts, including, an ex-model C school, an afternoon development centre that cares for learners from three of our participating schools, and a township school. The clubs have between six and 12 participating learners. In this paper, I report on the data in the smallest and first club established in 2012. The club is run from an afternoon development centre that caters for learners who require afternoon care, as their home situations do not enable this.

The clubs provide an after school informal learning space where we can engage directly with learners and research in more depth the nature of student numeracy learning and evolving proficiency. A focus of the clubs is on developing learner sense-making and shifting learner dispositions from being passive learners to more engaging, confident and actively participating learners (cf. Graven, 2011). A deliberate aim of the club is to create strong productive learning dispositions (defined below) within our clubs. The following table summarises some of the distinguishing features of the clubs, which is contrasted to the classroom environment. 
Table 1: Formal vs. informal learning environments (cf. Graven \& Stott, 2011: 95-96).

\begin{tabular}{|l|l|}
\hline \multicolumn{1}{|c|}{$\begin{array}{c}\text { Formal mathematics classroom/ } \\
\text { environment }\end{array}$} & Informal club/mathematics environment \\
\hline $\begin{array}{l}\text { Compulsory attendance is expected as part of } \\
\text { formal schooling (in-school-time). }\end{array}$ & $\begin{array}{l}\text { Voluntary membership during out-of-school } \\
\text { time. }\end{array}$ \\
\hline $\begin{array}{l}\text { Less learner choice over the activities that } \\
\text { they work on and engage with. }\end{array}$ & $\begin{array}{l}\text { More learner choice over the activities that } \\
\text { they work on and engage with. }\end{array}$ \\
\hline $\begin{array}{l}\text { Curriculum and assessment standards as a } \\
\text { prescriptive framework strongly influencing } \\
\text { choice of content and activities. }\end{array}$ & $\begin{array}{l}\text { Curriculum as contextual guide for what is } \\
\text { nationally expected of learners, but individual } \\
\text { learner numeracy levels guide content and } \\
\text { activities. }\end{array}$ \\
\hline $\begin{array}{l}\text { Largely acquisition based and often driven by } \\
\text { teaching for/to assessments. }\end{array}$ & $\begin{array}{l}\text { Participation based. Participants are active } \\
\text { and engaged. }\end{array}$ \\
\hline $\begin{array}{l}\text { Teacher led and much whole class teacher } \\
\text { learner interaction. }\end{array}$ & $\begin{array}{l}\text { Many interactions are learner led with few } \\
\text { whole class-mentor interactions and many } \\
\text { one-to-one interactions between mentors } \\
\text { and learners. }\end{array}$ \\
\hline $\begin{array}{l}\text { Assessment tends to be summative and } \\
\text { results in ranked performance. }\end{array}$ & $\begin{array}{l}\text { Assessment is formative and integrated and } \\
\text { used to guide individual learning experiences } \\
\text { for participants. }\end{array}$ \\
\hline $\begin{array}{l}\text { Prescriptive, teacher controlled classroom } \\
\text { rules within general school rules. }\end{array}$ & $\begin{array}{l}\text { Negotiated sociomathematical norms (Yackel } \\
\text { \& Cobb, 1996) which may differ from in- } \\
\text { school time rules. }\end{array}$ \\
\hline
\end{tabular}

\section{Reviewing the literature}

A key aspect of teacher pedagogical content knowledge (PCK) is knowledge of students (Shulman, 1986). Ball, Thames and Phelps (2008) distinguishes between two subdomains of PCK, namely knowledge of content and students, and knowledge of content and teaching. However, literature tends to focus on teachers' knowledge of learner's mathematical competence and less on what teachers know of learner mathematical confidence, forms of participation, or mathematical dispositions and identities.

Kilpatrick, Swafford and Findell (2001) highlight the importance of a productive disposition as one of the five interrelated strands of mathematical proficiency. The strands include: procedural fluency, conceptual understanding, adaptive reasoning, strategic competence and productive disposition. Productive disposition, as they define it:

... refers to the tendency to see sense in mathematics, to perceive it as both useful and worthwhile, to believe that steady effort in learning mathematics pays off, and to see oneself as an effective learner and doer of mathematics (Kilpatrick, Swafford \& Findell, 2001: 131). 
In the sense that productive disposition involves 'seeing oneself' as an effective learner and doer of mathematics, and that dispositions commonly refer to a habitual tendency to act in a certain way, they relate to learner forms of participation and ways of being in mathematics classes and to learner identities.

Kilpatrick, Swafford and Findell (2001) similarly define teaching proficiency in relation to the five interrelated strands that correspond to the five strands of mathematical proficiency. While they explain a productive mathematics teaching disposition in relation to teacher knowledge, practice and learning, they do not elaborate on this, and no link is made to knowledge of learner dispositions, or to how teachers might access learner dispositions or draw on them in their practice and learning. While it is acknowledged that knowledge of students involves knowing learners' levels of mathematical competence, and what they are able to do and not do, knowledge of student mathematical learning dispositions is generally ignored.

Similarly, mathematics assessments tend to ignore this aspect. Nationally administered numeracy assessments for young learners generally provide teachers with indicators of where learners are at in relation to the first two strands (cf. for example the Annual National Assessments (ANA's) (DoE, 2008)). On the other hand, some internationally designed orally administered assessments are more comprehensive and gather data that can be related to the first four strands (cf. Wright, Martland \& Stafford, 2006; and Askew, Rhodes, Brown, William \& Johnson, 1997). However, I have not as yet found assessments that incorporate the gathering of information about the nature of learner's mathematical learning dispositions. If this strand is, as Kilpatrick, Swafford and Findell (2001) suggest, one of five equally important interrelated strands of proficiency, then surely we need to find ways to support teachers to access and assess learner dispositions, in order to remediate and reinforce as needed. Assessing competence in the other strands may of course point towards a productive (or the absence of a productive) disposition, but the way in which dispositions relate to the other strands requires further investigation.

\section{Designing and piloting an instrument for accessing mathematical learning dispositions}

Since within our Chair we specifically aim to support learners to become mathematical sense-makers, mathematical negotiators and creative problem solvers, we aim to influence their way of being and their mathematical identities. Additionally we aim to improve learners' mathematical competence in terms of various assessable criteria that we have adapted and adopted from the Askew et al. (1997) and the Wright et al. (2006) interview-based numeracy instruments. These provide us with clear data that allows us to track learner progress (or regression) on various key numeracy competences. We have thus far been able to, although with much work and some 
difficulty; relate learner competences on these instruments to progression along a spectrum of proficiency for each of the first four strands (cf. Graven \& Stott, 2012).

In 2011 we piloted an instrument with our first pilot club. The instrument included a row of learners, which showed Mpho and Sam as the weakest and strongest learners, at either end of a spectrum, respectively. Learners were asked to point to where they were in the indicated spectrum of learners and to describe Mpho and Sam (cf. the start of the revised instrument in Figure 1 below). The instrument deliberately refers to providing a description of others (even while learners often followed descriptions of Sam or Mpho with "I am ...") as this enabled a 'safe' and less personal space where learners could articulate their views. The names Mpho and Sam were chosen to enable the interpretation of both male and female genders. Reference to Mpho and Sam was also intended to reduce the sense that we were assessing learners in the interview. For the evolution of the instrument see Graven (submitted).

The findings of the pilot in our Grade 3 club in 2011 with 10 learners enabled us to see how learners positioned themselves within the class in terms of their perceived mathematical strength or weakness. Several learners responded by saying, "I am Mpho" or "I am Sam", and when they described Sam and Mpho we were provided with inclinations of their stories about themselves. The data provided rich textured utterances on how learners perceived productive (and unproductive) learning dispositions. In this pilot club the dominant descriptor by learners for Sam was that s/he was someone who: listens to the teacher (6/10 learners), whereas working hard only received one reference across the responses. While not all learners provided responses for Mpho those who did described him/her in opposite terms to Sam, i.e. as not listening (4/10) (cf. Graven, subm.).

This enabled us to see the extent to which learner notions of an effective learning disposition were similar and/or different to the notion of a productive disposition. As a result, we were able to search utterances for indicators of criteria included in Kilpatrick, Swafford and Findell's (2001) definition of productive disposition, that is, we were able to determine whether learners "see sense in mathematics", "perceive it as useful and worthwhile", "believe that steady effort in learning mathematics pays off", and "see [themselves] as an effective learner and doer of mathematics". Aside from those learners who identified with Sam (and thus by implication identified themselves as being an effective learner) there was little to point towards productive dispositions, and thus we were able to say that at the start of the club learners' mathematical proficiency in relation to this strand was mostly absent or at best rudimentary. This influenced the design of our club activities.

Subsequent to the piloting we extended this instrument to include a few additional items as shown in our revised instrument: 


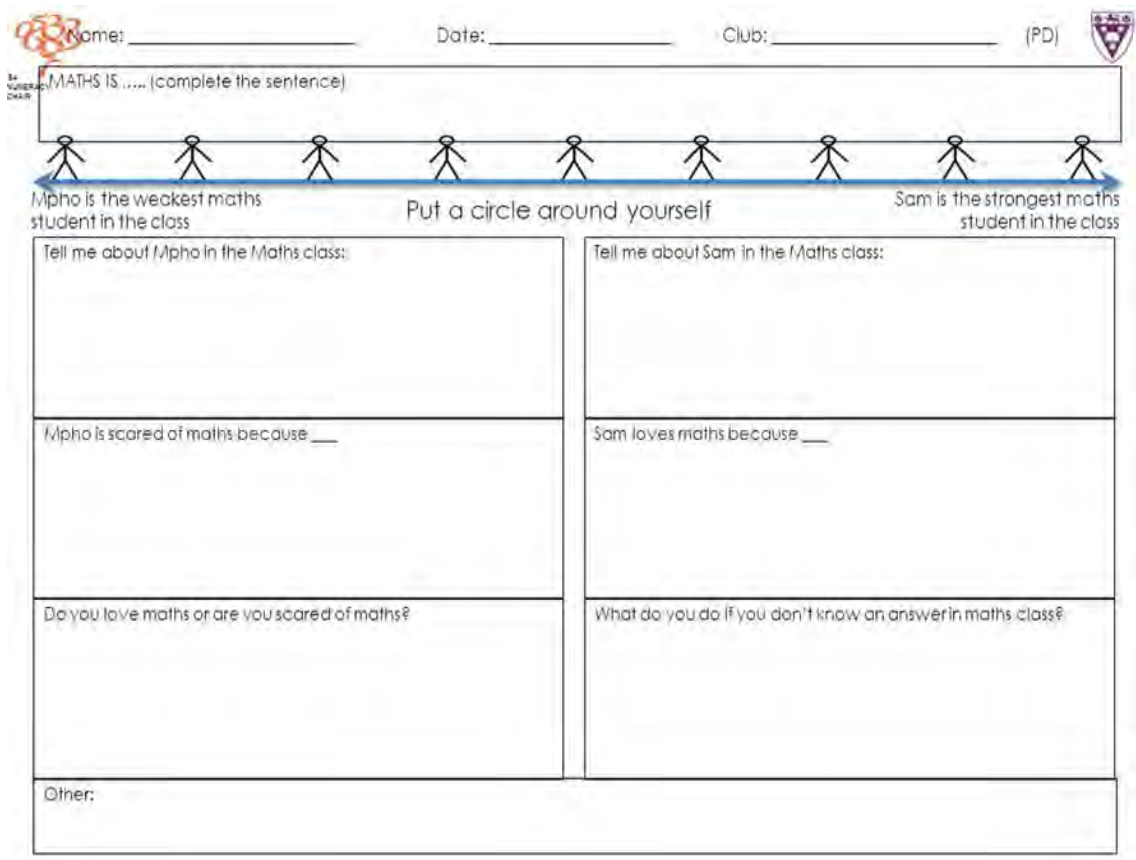

Figure 1: Revised mathematics learning disposition instrument.

While this instrument is generating rich data, and will hopefully enable us to see whether participation in mathematics clubs supports evolving productive learning dispositions, we supplement this data collection with recording of ongoing observational data. Reflective journal writing follows each club session, which includes notes of each learner's participation and proficiency as was observable in the club. These are later transferred to what we are calling 'individual learner story cards'.

\section{The findings from our first 2012 club}

Our first 2012 mathematics club began with only six learners. The instrument was used as a baseline interview and, where necessary, was translated into learners' home language. The small number of learners in this club allows me to report, with examples, on the findings across all six learners, so as to illuminate how the instrument enables us to access the mathematical learning dispositions of club members at the start of their participation in the clubs. This provides useful data in terms of planning activities so as to support establishing the club environment in order to meet the aims of maximising learner active participation, engagement, creative thinking and sense making. 
The instrument begins with a 'complete the sentence' item: "Mathematics is ..." This item aims to elicit responses that enable us to see how learners perceive mathematics and whether they perceive it as something 'useful' and 'worthwhile'. The six learner responses to this question indicated a perception of mathematics as the work/topic one does in the mathematics class. Two learners responded with simply "sums", while another three responded with: "two times table; work with numbers"; "words and numbers"; "work, tests and sums". One learner responded by explaining how the lesson unfolds by saying, "The teacher says it's time for mathematics, gives us books, then she writes on the board, then we must write the answer." The briefness of the responses provided limited insight into learners' perceptions. On the other hand, when compared to a much wider range of responses across other clubs, which included descriptors of learner experiences of mathematics with responses such as: "fun", "awesome", "nice", "good", "important" and descriptors of "all about thinking" or explanations of how it relates to everyday problems to be solved, one becomes aware that the limited range of responses might indicate a relatively impoverished view of what mathematics is all about. Both the presence and absence of utterances provide us with information that influences our design of club activities. For more on the nature of the club design process see Graven and Stott (2012). The limited range of responses also contrast with the more elaborated Curriculum Assessment and Policy Statement (CAPS) definition of mathematics, which emphasises that it is a human activity involving processes that “... enhance logical and critical thinking, accuracy and problem solving that will contribute to decision making” (DBE, 2011: 8). Of course learners in Grade 3 would not be expected to elaborate with this type of discourse, but suggestions of connections to real life, problem solving, thinking and so forth would have implied more coherence with the curriculum view of what mathematics is.

The questions that ask the learners to tell us about Mpho and Sam in the mathematics class revealed factors that learners saw as influencing weakness or strength in mathematics. Mostly the learners described Mpho as someone who was disruptive in some way in class for example: "Plays in class" (three learners referred to this), "talks a lot and fights", "makes a noise, he throws things around the class", etc. One learner referred to non-participation in writing: "He doesn't write. He watches other children write." While one learner, I will call him Jami, explained Mpho as doing the work, but feeling bad due to his weakness: "He writes the mathematics. He feels bad. He does his homework every day." He also contrasted this to Sam who got everything right, but "does his homework sometimes". What is communicated in this case is an experience that diligence in doing ones work every day does not necessarily lead to mathematical strength (I will come back to Jami later in this paper when I relate his responses on this instrument to his performance on other instruments). On the other hand, the learners viewed Sam in terms of doing the work he was told to do and writing what was required. For example one learner explained: "He takes everything he needs when the teacher tells him to and he writes all the things she writes and he finishes it." 
Similarly, the 'complete the sentence' items relating to Mpho and Sam, being scared of mathematics and loving mathematics respectively “... because ...", provided insight into what learners saw as significant influences on learning experiences. Most of the learners (4/6) in this club answered in terms of getting sums/work right or wrong. For example: "He's scared he gets everything wrong" for Mpho and "he gets everything right" for Sam. One learner related being scared or loving mathematics to not doing or doing the work: "He doesn't do the work" and "because he does it every day", respectively. Contrasting this notion that fear or love of mathematics depends on the extent of work done, one learner related this innate ability by giving the reasons of "being stupid" and "being clever" respectively. The question asking learners if they loved or were scared of mathematics was simply answered in terms of "I love mathematics" or "I like mathematics" or in one case "I am clever". It is difficult, however, to ascertain the extent to which learners felt compelled to answer this as they were participating in a voluntary mathematics club, which expressly claimed that it aimed to get students to enjoy and love mathematics more.

The final question on the instrument: "What do you do if you don't know an answer in mathematics class?" possibly provided us with the richest data in terms of understanding a range of possible dispositions across learners in our various clubs. It gave us a sense of the extent of learner independence and the extent to which they saw themselves as mathematical generators, or problem solvers, and the extent to which they viewed their role in the mathematics class as being passive receivers of knowledge and followers of instruction. These are not mutually exclusive as learners can of course perform multiple roles in class, but the instrument allowed us to see which roles were foregrounded. This question helps to distinguish learners who predominantly position themselves as having the agency to solve the 'unknown' problem (through for example drawing on their own thinking or methods) from those who position the solution to the unknown as residing with the teacher or someone else, thus indicating less independence in relation to learning dispositions.

In this club all of the six learners suggested asking someone. For example, five of the six learners suggested drawing on the teacher: "Ask your teacher", "put up your hand and the teacher will explain", "stick up my hand. Have to wait", while one learner said "I must ask someone - l'll ask my friend”. While one might of course expect such answers, and of course in many cases I have given this advice to learners that I have helped with mathematics, the absence of utterances that indicate that one might find a way forward by drawing on one's own resources is significant. The responses of the learners in this thus contrasts, for example with the much wider range of utterances we received from learners in a different club in a high performing school (in terms of ANA's and Chair assessments). In this club only two learners suggested asking the teacher and the remaining eight learners referred to ways of solving that did not involve the teacher, e.g. "I thought in my mind", "I work it out", "I take scrap paper or counters or my brain", "stretch my brain a bit and don't copy."

The addition of this question about what students do when they don't know an answer gives rich data that informs club facilitators of club members "ways of being" 
(Wenger, 1998) mathematics learners and a sense of the extent to which they have developed a "productive disposition" (Kilpatrick et al., 2001). While it gives insight into this for each learner, it also provides insight into the way in which certain dispositions are promoted across classrooms and schools that we work with in the South African Numeracy Chair. While the case study nature of our club research prevents me from arguing that there may be a causal relationship between learner dispositions and performance on certain mathematical activities, such as problem solving, I would argue that this is an area of research that requires further investigation. Indeed within Kilpatrick et al.'s (2001) five strand definition of mathematical proficiency, productive disposition is intertwined with proficiency in the other strands and in this sense a relationship between them is assumed. However, there is little research that elaborates on the nature of this relationship and how knowledge of learner dispositions might be used to support the design of rich learning opportunities across the strands of proficiency.

The final item on the instrument allowed learners the opportunity to input freely anything they wished to share with the interviewer in relation to mathematics. Since the input was optional, learners tended to decline a response. In this club only one learner volunteered a response to this open item answered "Ek wil net slaag", which translates as "I just want to pass".

In terms of our mathematics club focus on developing positive and confident learning dispositions, we embrace learner errors and highlight that they provide rich learning opportunities. We emphasise that there is no shame in not knowing, as we are all learners, and it is because there is always much that we do not know that we come together to learn. Thus emphasising the Socratic philosophy, that it is better to know what you do not know than to think you know, we encourage learners to share and articulate what they do not know.

Additionally, we emphasise the importance of thinking independently and finding ways to solve problems using creative thinking and multiple methods. Think-pair-share is a strategy we use regularly to get learners to begin with independent thinking and their own sense-making, then pairing and sharing encourages engagement, discussion of different methods and argumentation over solutions. The facilitator stimulates discussion and sense-making where necessary, but learners are first encouraged to think independently and then in pairs before drawing on the facilitator for support or acknowledgement.

In our clubs we consider learner mathematical histories rather than work with notions of learner abilities and reject the notion that a learner may be mathematically stupid and instead focus on the ways in which learners learn and their disposition towards learning. This concurs with Askew et al.'s (1997) finding that 'effective' numeracy teachers believe that almost all children are able to become numerate, and ensure that all students are challenged and stretched, not just those perceived to be more able. Thus, in this club we would hope that with time learners would begin to provide responses indicating a rich connected understanding of mathematics and 
mathematics competence, in terms of the processes and ways in which learners approach and tackle problems, and with regards to their willingness to participate in meaningful engagement in mathematics learning.

Above I have included the data of all six learners on each item of the instrument in order to illuminate what each part of the instrument allows us to see. I have contrasted learner responses with some of the responses in other clubs in some parts, because it is sometimes only by comparison to other possibilities that absences are illuminated and one is able to see that a disposition may be constrained or dependent. While it is not possible in this paper to provide overview stories of each learner in the club across the disposition instrument, and across our other instruments we use to assess procedural fluency, conceptual understanding, adaptive reasoning and strategic competence, it will be useful to elaborate more on Jami (mentioned above) as an example of a story that we are able to glean through our combined instruments at the start of this club. I turn to this briefly in the next section.

\section{Looking at one learner across the instrument and strands}

Jami performed poorly on almost all items assessing mathematical proficiency. In Wright et al.'s (2001) terms Jami's number sense was largely in the 'perceptual/initial' stage. That is along the six stages ranging from stage o (emergent) to stage 5 (facile) Jami demonstrated mostly stage 1 competences. I conducted the interview and noted that he tried his best on all items, and while he could have opted to say he did not know for some items, he tended to try everything. In Kilpatrick et al.'s (1997) terms he displayed weak procedural fluency, weak conceptual understanding, and almost no strategic competence or adaptive reasoning. After the interview, I discussed his case with our team of interviewers and said that I was struck by his repeated insistence at counting everything in ones. I referred to an item we used from Wright et al. (2001) where we place strips of dots out in front of the learner and asked "how many?" One first places a strip of dots with four dots, then one adds another strip of dots with 10 dots and asks, "now how many?" One continues to add strips of ten and asking "now how many?" until there are 74 dots altogether.

I was amazed that Jami continually went back to counting from the beginning of the four dot strip each time I asked, "now how many?" and counted all the dots in 15 touching each one as he counted. Many learners that I have conducted this interview with, who begin by counting in ones for the first few questions, usually progress to adding in tens or counting on from the previous answer at some point in the questioning process. I considered that the learner did not do this, even though I suspected he was capable of figuring this out as a more efficient method during the interview process, because he did not believe he had the freedom to depart from the concrete method within the school context. I suspected that he thought the required method for doing this type of problem was to show one's counting from the beginning and to convince the teacher or adult by touching each dot as one counted. I got the sense that unless he was told to count 'in tens' or to 'count on' it 
would not occur to him that this was 'allowed'. He smiled at me with a deep breath before embarking on touching and counting all seventy four dots in the final question. At present this research has not focused on the influence of classroom teaching on learner dispositions, but I see this as an important avenue that requires exploration.

Jami's seemingly restricted learning disposition that involved doing what one believed was required, rather than experiencing the freedom to draw on one's own sense-making, and actively generating the direction of one's learning through creative decisions in the process of doing mathematics haunted me for several days as I suspected that Jami's hard working, compliant and willingness to please disposition were, ironically, most likely restricting his progress. This concurred with his response on the learning disposition instrument when he indicated in response to what he does if he does not know an answer that he would "... stick my hand up. Have to wait". This relatively passive teacher dependent learning disposition will more than likely stifle his progress in mathematical sense making.

Indeed he may fear finding his own solution in case it departs from the teachers. It seems Jami is somewhat aware that his hard work might not result in success as his utterances describing Mpho indicated that Mpho felt bad despite writing the mathematics and doing his homework everyday (discussed above). For the "mathematics is ..." item Jami simply responded "sums", and for "Do you love mathematics" he watered it down with "I like mathematics".

I would argue that the instruments give us a picture of how Jami's disposition is intertwined with his mathematical performance on the other strands and indicates ways in which we need to support Jami in strengthening his mathematical proficiency. I would argue that it is important that as club facilitators we find ways to shift Jami's restricted learning disposition to one which more confidently explores his personal sense-making and methods. Without this I suspect that his belief that 'hard work' and doing homework does not necessarily pay off might in time result in non-participation. This was evidenced in earlier research with mathematical literacy learners who told stories of non-participation, as a result of experiences that hard work and effort did not lead to sense making, and thus did not pay off (cf. Graven \& Buytenhuys, 2011).

\section{Conclusion}

A key aim of our setting up of mathematics clubs is to interrupt ${ }^{1}$ what we perceive to be a passive overly teacher dependent culture of learning mathematics. We hope to interrupt notions that mathematics learning must be teacher led or initiated by a clear teacher method or instruction. We wish to de-emphasise current motivations for mathematics participation that are seemingly dominated by compliance with teacher instructions and getting answers right. We hope to supplement this with engendering a motivation that is more intrinsic to the process of learning and to reveal that the gains of mathematical sense-making and learning include both personal development and mathematically capable participation in society, more generally. We hope to 
engender a love of challenging oneself mathematically and learning mathematics for solving problems in creative ways both in, and outside of, school.

We wish to develop learners, in keeping with the new curriculum, who have:

- critical awareness of how mathematical relationships are used in social, environmental, cultural and economic relations;

- the confidence and competence to deal with any mathematical situation without being hindered by fear of mathematics;

- a spirit of curiosity and a love of mathematics; appreciation of the beauty and elegance of mathematics; recognition that mathematics is a creative part of human activity;

- a deep conceptual understanding in order to make sense of mathematics; and

- the acquisition of specific knowledge and skills necessary for:

- the application of mathematics to physical, social and mathematical problems;

- the study of related subject matter (e.g. other subjects); and

- further study in mathematics (DoE, 2011: 8).

Additionally we hope that our research in clubs might feed back into classrooms ways in which teachers might support learners in nurturing such dispositions.

It would seem from this early data of the six learners participating in this club that notions of compliance dominate at the expense of the achievement of these broader aims of mathematics as a subject in the foundation phase. Learners view teacher dependence and compliance as key to their success and while this has a place in learning it cannot overshadow the need to develop learners capable of independent, critical and creative thinking, which are important for developing all five strands of mathematical proficiency. Additionally such thinking is required for participation in society and democratic citizenship.

A hypothesis might be that learners with learning dispositions that are overly compliant and teacher dependent would be less likely to develop strength in the strands of conceptual understanding, strategic competence and adaptive reasoning as these require, by their definition, learners to make sense of mathematics and to think critically and creatively. While this makes intuitive sense, and resonates with my own teaching experience, larger scale research is required to explore the complexity of the relationship between this strand and others. The broader research across the clubs in the South African Numeracy Chair will explore this relationship further.

\section{Acknowledgement}

I thank the team of researchers within the South African Numeracy Chair, Rhodes University for their on-going collaboration and particularly Debbie Stott with whom I 
am working closely with to research learning within our mathematics clubs. The work of the South African Numeracy Chair, Rhodes University is supported by the FirstRand Foundation (with the RMB), Anglo American Chairman's fund, the Department of Science and Technology and the National Research Foundation.

\section{Endnote}

1. Professor Adler at the FirstRand Mathematics Education Chair Community of Practice forum held in Cape Town (30/11/2010) argued in her presentation that we have to 'interrupt' the learning and teaching culture in schools where learners are passive, learning is teacher dependent and the focus of teaching is on 'compliance'.

\section{References}

Askew, M., Brown, M., Rhodes, V., Johnson, D. \& William, D. (1997). Effective teachers of numeracy. London: London: King's College/TTA.

Ball, D. L., Thames, M. H. \& Phelps, G. (2008). Content knowledge for teaching: What makes it special? Journal of Teacher Education, 59(5): 389-407.

Carnoy, M., Chisholm, L., Addy, N., Arends, F., Baloyi, H., Irving, M., Raab, E., et al. (2011). The process of learning in South Africa: The quality of mathematics teaching in North West Province. Technical report, 11 June 2011. Stanford University School of Education \& HSRC.

Department of Basic Education (DBE). (2011). Curriculum and Assessment Policy Statement Grades 1-3 mathematics. Department of Basic Education, Pretoria.

Department of Education (DoE). (2008). 2007 Grade 3 systemic evaluation. Pretoria.

Department of Education (DoE). (2003). National Curriculum Statement Grades 10-12 (General): Mathematical literacy. Department of Education, Pretoria.

Fleisch, B. (2008). Primary education in crisis: Why South African schoolchildren underachieve in reading and mathematics. Johannesburg: Juta.

Freedman, J. \& Combs, G. (1996). Narrative Therapy: the social construction of preferred realities. W.W. Norton \& Company, New York.

Graven, M. (2011). Creating new mathematical stories: exploring opportunities within mathematics clubs. Proceedings of $17^{\text {th }}$ National Congress of the Association for Mathematical Education of South Africa (AMESA) (pp. 161-170). Johannesburg: University of the Witwatersrand.

Graven, M. (2009). Wenger's (1998) perspective on learning is 'ready for prime time' in some mathematical literacy classrooms. Proceedings of the $17^{\text {th }}$ Annual meeting of the Southern African Association for Research in Mathematics, Science and Technology Education, Rhodes University, 1, pp. 71-81.

Graven, $M$. (submitted) Developing an instrument for researching early mathematical identities and dispositions. 
Graven, M. \& Buytenhuys E. (2011). Mathematical literacy in South Africa: Increasing access and quality in learners' mathematical participation both in and beyond the classroom. In: B. Atweh, M. Graven, W. Secada \& P. Valero (eds.), Mapping Equity and Quality in Mathematics Education. Springer: Heidelberg, pp. 493-509.

Graven, M. \& Stott, D. (2012). Design issues for mathematics clubs for early grade learners. In: D. Nampota \& M. Kazima (eds.), Proceedings of the 20th Annual Meeting of the Southern African Association for Research in Mathematics, Science and Technology Education (pp. 94-105). Lilongwe: University of Malawi.

Graven, M. \& Venkatakrishnan, H. (2006). Emerging successes and tensions in the implementation of mathematical literacy. Learning and Teaching Mathematics, 4:5-9.

Kilpatrick, J., Swafford, J. \& Findell, B. (2001). Adding it up: Helping children learn mathematics. Washington DC: National Academy Press.

Sfard, A. \& Prusak, A. (2005). Telling Identities: In Search of an Analytic Tool for Investigating Learning as a Culturally Shaped Activity. Educational Researcher 34(4): 14-22.

Shulman, L. S. (1986). Those who understand: Knowledge growth in teaching. Educational Researcher, 15(4).

Southern and Eastern Africa Consortium for Monitoring Educational Quality (SACMEQ). (2010a). SACMEQIII Project Results: Pupil achievement levels in reading and mathematics. Working document Number 1, SACMEQ, 2010.

Southern and Eastern Africa Consortium for Monitoring Educational Quality (SACMEQ) (2010b). SACMEQIII Project Results: Pupil achievement levels in reading and mathematics. Working document Number 1.

Wenger, E. (1998). Communities of Practice: Learning, Meaning, and Identity. Cambridge University Press: New York, USA.

Wright, R. J., Martland, J., Stafford, A. K. \& Stanger, G. (2006). Teaching Number: Advancing children's skills and strategies ( $2^{\text {nd }}$ ed.). London: Paul Chapman Publishing Ltd.

Yackel, E. \& Cobb, P. (1996). Sociomathematical norms, argumentation and autonomy in mathematics. Journal for Research in Mathematics Education, 27: 458-471. 